\title{
Physical Fitness Swimming Athlete In UNSIKA
}

\author{
Ruslan Abdul Gani ${ }^{1)}$, Irfan Zinat Achmad ${ }^{2)}$ \\ ${ }^{1,2}$ Program Studi Pendidikan Jasmani Kesehatan dan Rekreasi \\ Fakultas Keguruan dan Ilmu Pendidikan \\ Universitas Singaperbangsa Karawang, Jawa Barat Indonesia \\ Email: ${ }^{1}$ ruslan.abdugani@staff.unsika.ac.id, ${ }^{2}$ irfanza@ fkip.ac.id
}

\begin{abstract}
This study aims to determine the level of fitness conditions in the students who become athletes in swimming UNSIKA. This research used was to use a method of extracting information field (survey) quantitative research. Sampling is done using saturated sampling, meaning that the entire population is a member of the sampling. Number of samples research were 20 male students The instrument is used by referring to Norms and guidelines for assessing physical fitness levels standard for16-19 years. Results of this study that the level of physical fitness of UNSIKA swimming athletes must continue to be improved because with the level of fitness that does not match the appearance of swimming athletes will affect the results of swimming when participating in competitions at the college level, the level of physical fitness condition of swimming athletes is influenced by the adaptation of athletes accustomed to in a swimming pool that makes the results of physical fitness is not expectations at a good level of physical fitness. The conclusion of this study is the level of physical fitness conditions on students members of UNSIKA swimming are in the Medium classification.
\end{abstract}

Keywords; Physical Fitness, Swimming, Fitnes Swimming Program

\section{Tingkat Kebugaran Jasmani Atlet Renang UNSIKA}

\section{ABSTRAK}

Penelitian ini memiliki tujuan mengetahui tingkatan kondisi derajat kebugaran pada mahaiswa yang menjadi atlet di UKM Renang. Penelitian ini yang dipakai adalah dengan menggunakan cara penggalian informasi kel apangan (survey) jenis penelitian kuantitatif. Penarikan sampel dilakukan menggunakan sampling jenuh, dalam arti keseluruhan populasi menjadi anggota sampling. Jumlah sampling yang menjadi subjek penelitian sejumlah 20 mahasiswa putra. Instrumen yang digunakan dengan mengacu kepada norma dan panduan penilaian tingkat kebugaran jasmani yang sudah baku pada umur 16-19 tahun. Hasil dari penelitian ini bahwa tingkat kebugaran jasmani atlet renang UNSIKA harus terus ditingkatkan karena dengan tingkat kebugaran yang tidak sesuai standart penampilan atlet renang akan mempengaruhi hasil berenang pada saat mengikuti perlombaan di tingkat perguruan tinggi, tingkat kondisi kebugaran jasmani atlet renang dipengaruhi juga oleh adaptasi atlet yang terbiasa di kolam renang yang menjadikan hasil kebugaran jasmani tidak sesuai dengan harapan yaitu pada tingkat kebugaran jasmani yang baik. Kesimpulan dari penelitian ini adalah tingkatan kondisi kebugaran jasmani pada mahsiswa yang tergabung dalam UKM renang UNSIKA berada pada klasifikasi Sedang.

Kata Kunci; Kebugaran Jasmani, Renang, Program Kebugaran Renang

Info Artikel

$\begin{array}{ll}\text { Dikirim } & : 14 \text { April } 2020 \\ \text { Diterima } & : 28 \text { April } 2020 \\ \text { Dipublikasikan } & : \text { 11 Mei } 2020\end{array}$

(C) 2020 IKIP BUDI UTOMO MALANG

P-ISSN 2613-9421

E-ISSN 2654-8003

\Alamat korespondensi: ruslan.abdugani@staff.unsika.ac.id

Universitas Singaperbangsa Karawang, Jl. HS.Ronggo Waluyo, Puseurjaya, Kec.

Telukjambe Tim., Kabupaten Karawang, Jawa Barat 41361, Indonesia 


\section{PENDAHULUAN}

Olahraga adalah kebutuhan bagi manusia dalam kehidupan, supaya keadaan fisik dan derajat sehatnya terjaga secara baik (Prasetyo, 2013), kebugaran jasmani merupakan unsur paling utama pada saat melaksanakan suatu kegiatan gerak fisik, dengan memiliki kualitas tubuh yang bugar dan prima maka akan dipastikan mampu menyelesaikan tugas dengan tidak terlalu merasa lelah pada tubuhnya atau tidak terlalu berarti, tingkat produktifitas yang baik ditentukan oleh tingkat kebugaraan jasmaninya (Saputro, 2018). Keadaan tubuh yang bugar akan bisa mengerjakan pekerjaan dengan maksimal dan tidak banyak waktu yang terbuang merupakan dampak dari kebugaran jasmani (Nugroho, 2017). Umumnya kebugaran jasmani disebut juga dengan kebugaran tubuh atau fisik ( physical fitness), apabila keadaan fisik peserta didik sehat dan bugar dipastikan tingkat konsentrasi akan lebih meningkat pada saat proses interaksi pembelajaran di kelas (Satrio \& Winarno, 2019).

Kebugaran jasmani merupakan derajat kebugaran manusia untuk melaksanakan aktivitas kesehariannya dengan efektif dan efisien dengan tidak merasa kelelahan dan masih tersisa energinya guna keperluan dalam waktu luangnya (Wirnantika, Pratama, \& Hanief, 2017), apabila kesegaran jasmani seseorang bagus maka dapat dipastikan akan mampu melaksanakan aktifitas kesehariannya akan optimal, tidak mudah lelah, dan mempunyai simpanan energi untuk melakukan aktifitas berikutnya (Prayuda \& Firmansyah, 2017). Kebugaran jasmani atlet renang menjadi sangat penting bagi penampilan puncak prestasi atlet pada saat mengikuti perlombaan, dalam penelitian ini yang menjadi hal penting adalah kondisi kebugaran atlet renang UNSIKA yang masih jauh dari harapan standart kebugaran jasmani atlet renang dalam berkompetisi antar perguruan tinggi.

Kebugaran jasmani diperlukan bagi seseorang agar disetiap melakukan aktifitasnya atau mengerjakan tugas dapat diselesaikan dengan efektif dan efisien (Nugraheningsih \& Saputro, 2019). Kondisi kebugaran jasmani itu merupakan suatu keharusan bagi manusia dalam hidup supaya tubuh kita sehat dan produktif (Rusdi, Arifin Zainal, 2016). Kebugaran Jasmani merupakan suatu aktifitas fisik yang dilakukan dengan melibatkan aspek fisik seperti kemampuan otot yang kuat 
(strength), ketahanan tubuh selama melakukan aktifitas dengan waktu yang lama (endurance) dan kelenturan (fleksibilitas) (Pratiwi, Setijono, \& Fuad, 2018). Kebugaran jasmani ialah kesanggupan kondisi fisik dalam beradaptasi terhadap beban yang diberikan kepada seseorang dalam beraktifitas sehari-hari dengan tidak memunculkan kelelahan yang berlebihan (Sepriadi, 2017). Kebugaran jasmani yang tinggi didapat dari proses aktifitas yang dilakukan setiap hari, dengan melakukan olahraga yang terprogram dan terencana (Dartini, Sucita Dwi Putu Ni, Suwiwa, Gede I, 2017).

Olahraga adalah aktifitas fisik yang dilakukan dengan tujuan sebagai pemeliharaan tubuh supaya sehat, menguatkan otot anggota tubuh. Aktifitas ini dilakukan dengan suasana hiburan, senang dan ceria atau bisa juga menuju peningkatan ke arah prestasi (Supriyoko \& Mahardika, 2018). Berdasarkan dari argumentasi tersebut diatas yang dimaksud dengan kebugaran jasmani ialah aspek penting dalam olahraga, dikarenakan apabila atlet mempunyai kondisi tubuh yang bugar dan sangat bagus akan dapat melaksanakan atau mengerjakan kegiatan latihan kesehariannya maupun pada saat pertandingannya akan optimal. Sangat pentingnya kebugaran jasmani bagi atlet renang karena untuk meningkatkan penampilan fisiknya dalam pencapaian prestasi yang tinggi (Wahyudi, Andra, Rahayu Kaswarganti, 2015).

Cabang nomor perlombaan renang ialah cabang nomor terukur dan termasuk popular dimasyarakat, aspek kebugaran jasmani pada cabang renang sangat diperlukan karena pada saat kita berenang semua komponen fisik diperlukan, maka atlet renang harus memiliki keterampilan untuk meningkatkan performanya. Renang termasuk kedalam olahraga prestasi dalam olahraga prestasi diperlukan program latihan yang baik agar tujuan prestasi dapat tercapai, olahraga prestasi ialah olahraga yang terprogram secara terencana dan memiliki tujuan dan target tertentu sesuai dengan tujuan latihannya guna tercapainya penampilan puncak prestasi atlet (Kusuma Wijaya, 2019). Olahraga renang berbeda dengan olahraga lainnya, dalam berenang ada aspek dan pola yang harus diperhatikan seperti pola bernafas dan otot yang bekerja pada saat berenang (Lazar, Khanna, Chesler, \& Salciccioli, 2013). 
Peningkatan performa atlet renang dapat dilakukan dengan program latihan yang terencana dan tersusun dengan baik agar pencapaian prestasinya bisa tercapai, komponen dalam program latihan yang paling penting ada empat aspek diantaranya (1) aspek fisik, (2) aspek teknik, (3) aspek taktik, dan (4) aspek mental (Mubarok, 2019). Dalam pencapaian suatu prestasi olahraga harus ada usaha yang dilakukan dan dapat diukur melalui pembinaan dari dini, keterampilan secara teknik, taktik, dan strategi serta dengan pendekatan yang sesuai agar tercapai tujuan latihannya (Pujianto, 2015). Berdasarkan argumentasi diatas ditarik kesimpulan bahwasannya keberhasilan dari sebuah latihan ditentukan oleh para pelatih dalam membuat perencanaan program latihan secara terencana, tersusun, dapat diukur berdasarkan pada karakteristik atlet dan dengan mengacu pada prinsip latihan serta 4 aspek dalam latihan.

Peran pelatih sangat menentukan dari peningkatan kebugaran jasmani atletnya dengan membuat program pelatihan dengan tersusun secara sistematis terencana secara bagus, pasti keterampilan dan kondisi kebugaran fisik atletnya akan sangat baik. Penelitian ini bertujuan mengetahui tingkat kondisi bugar mahasiswa UKM Renang di UNSIKA menggunakan alat ukur tes kebugaran jasmani (TKJI), berdasarkan hasil pengamatan dan observasi di lapangan belum sesuai dengan harapan kondisi kebugaran jasmani atlet renang UNSIKA yang berpengaruh dalam penampilan atlet.

Dari hasil bahasan tersebut peneliti tertarik ingin meneliti bagaimana tingkat kebugaran jasmani atlet UKM Renang UNSIKA. Penelitian ini juga telah dilakukan oleh (Iskandar, 2014) dengan Judul Penelitian "Survey Tingkat Kebugaran Jasmani Mahasiswa Baru Penjaskes STKIP-PGRI Pontianak Tahun 2013" dengan data dari penelitiannya adalah klasifikasi baik sekali pada prosentase $0 \%$, klasifikasi baik sekitar 10 orang (16,13\%), klasifikasi sedang sekitar 45 orang ( $72,58 \%)$, klasifikasi kurang sekitar 6 orang $(9,68 \%)$, dan klasifikasi kurang sekali ada 1 orang $(1,61 \%)$. Secara penelitian sama mengukur tingkat kebugaran jasmani namun sampel berbeda peneliti mengukur tingkat kebugaran jasmani di tingkatan mahasiswa khususnya mahasiswa yang tergabung dalam UKM Renang. Penelitian ini menarik karena meneliti tingkat kebugaran jasmani atlet renang yang terbiasa dilakukan di kolam renang, peneliti lakukan tes 
kebugaran jasmani di darat. Kebaruan dari penelitian ini adalah mengukur tingkat kebugaran jasmani atlet renang di darat dengan menggunakan norma Tes Kebugaran Jasmani Indonesia(TKJ) pada usia 16-19 tahun.

\section{METODE}

Proses dalam melakukan penelitian ini dengan memakai metode survey dan pendekatan deskriptif kuantitatif. populasi dalam penelitian ini ialah mahasiswa yang tergabung dalam Unit Kegiatan Mahasiswa (UKM) Renang UNSIKA yang berjumlah 20 orang. Adapun Penarikan anggota sampling menggunakan sampling jenuh. Sampling jenuh merupakan teknik pengambilan sampel dari semua populasi yang ada dijadikan anggota sampel (Tarsito, 2014). Teknik pengumpulan data menggunakan tes Kebugaran Jasmani Indonesia untuk umur 16-19 tahun yaitu meliputi: (1) sprint $60 \mathrm{~m}$, (2) pull up 60 detik, (3) sit-up 60 detik, (4) vertical jump, (5) Lari 1200 meter (Fenanlampir, Faruq, 2015). Teknik dalam analisis data menggunakan deskriptif presentasi menggunakan kriteria kelompok dengan klasifikasi baik sekali, baik, sedang, kurang dan kurang sekali. dengan menggunakan penghitungan Deskripsi Prosentase (Hanief \& Himawanto, 2017)

\section{HASIL DAN PEMBAHASAN}

Dalam penelitian ini alat ukur yang digunakan dengan menggunakan Tes Kebugaran Jasmani Indonesia (TKJI) nama tesnya diantaranya adalah: (1) sprint $60 \mathrm{~m}$, (2) pull up 60 detik, (3) sit-up 60 detik, (4) vertical jump, (5) Lari 1200 meter. Dari data yang terkumpul dan hasil perhitungan bahwa adanya perbedaan kemampuan kondisi kebugaran jasmani mahasiswa UKM Renang UNSIKA pada skor tertinggi 22 dan skor terendah 8. 
Tabel 1. Data Klasifikasi Tes Kebugaran Jasmani

\begin{tabular}{|c|c|c|c|c|}
\hline No & Jumlah Nilai & Klasifikasi & Frekwensi (f) & Prosentase (\%) \\
\hline 1 & $22-25$ & Baik sekali (BS) & 2 & $10 \%$ \\
\hline 2 & $18-21$ & Baik (B) & 4 & $20 \%$ \\
\hline 3 & $14-17$ & Sedang (S) & 7 & $35 \%$ \\
\hline 4 & $10-13$ & Kurang (K) & 4 & $20 \%$ \\
\hline 5 & $5-9$ & Kurang Sekali (KS) & 3 & $15 \%$ \\
\hline \multicolumn{3}{|c|}{ Jumlah } & $\sum \mathbf{f}=\mathbf{2 0}$ & $100 \%$ \\
\hline & & & $\begin{array}{l}\text { "Baik Sekali } \\
\text { = Baik } \\
\text { "Sedang } \\
\text { "Kurang } \\
\text { " Kurang Sekalí }\end{array}$ & \\
\hline
\end{tabular}

\section{Gambar 1 Hasil Tes Kebugaran Jasmani Mahasiswa UKM Renang UNSIKA} Tahun 2020

Berdasarkan Pada tabel 1 dan gambar 1, terlihat bahwa kondisi kebugaran jasmani mahasiswa klub renang UNSIKA yang berjumlah 20 orang, yang berada pada klasifikasi baik sekali 2 orang (10\%), pada klasifikasi Baik 4 orang (20\%), pada klasifikasi sedang 7 orang (35\%), pada klasifikasi kurang ada 4 orang (20\%), dan pada kategori kurang sekali ada 3 orang (15\%). Hasil dari penelitian bahwa tingkat kondisi kebugaran jasmani atlet renang UNSIKA ada pada klasifikasi sedang dengan jumlah 7 orang sekitar $35 \%$.

Dengan kondisi kebugaran jasmani atlet renang UNSIKA yang berada pada kategori sedang (7 orang atau sekitar 35\%) ini menjadi perhatian khusus bagi pelatih renang UNSIKA harus dapat terus meningkatkan kualitas kebugaran jasmani karena olahraga renang memerlukan kondisi kebugaran yang baik karena olahraga renang termasuk kedalam olahraga terukur dan membutuhkan ketahanana fisik yang kuat karena dalam perlombaan renang ada beberapa nomor sprint jarak menengah dan jarak jauh. Ini merupakan hal yang harus ditingkatkan karena olahraga renang membutuhkan kondisi kebugaran yang prima atlet renang selain harus memiliki keterampilan dalam berenangnnya harus ditunjang juga 
dengan kondisi fisik dan kebugaran yang optimal supaya dapat menyelesaikan renangannya sesuai dengan target dari pelatih dan meraih prestasi sesuai dengan harapan, ini merupakan tugas dari pelatih supaya para atletnya mampu bersaing dengan atlet dari perguruan tinggi di indonesia. Kebugaran jasmani merupakan pondasi bagi atlet dalam latihannya (Catikkas, 2016). Kondisi Kebugaran atlet juga dipengaruhi oleh kondisi fisik atlet diantaranya indeks masa tubuh, kekuatan otot, sistem syaraf, keterampilan, koordinasi gerak kekuatan anaerob dan daya tahan (Pyne \& Sharp, 2014).

Kebugaran jasmani memiliki beberapa komponen tes diantaranya adalah Tes Daya tahan, Tes Kecepatan,Tes Kekuatan. Tingkat kebugaran memiliki hubungan dengan kesehatan karena ada 4 komponen dasar yang sama diantara adalah daya tahan jantung paru, kekuatan dan daya tahan otot, kelenturan dan komposisi tubuh (Yudianti, 2016). Kondisi kebugaran seseorang dapat ditingkatkan dengan adanya pelatihan yang terprogram dengan baik, prestasi atlet sangat ditentukan oleh faktor latihan, dengan pelatihan program kebugaran jasmani tersebut akan dapat mempengaruhi perkembangan dan pertumbuhan fisiologisnya sehingga akan menghasilkan peningkatan prestasi yang lebih baik. Dalam pencapaian derajat kebugaran jasmani supaya lebih maksimal harus intensif dalam melaksanakan program latihan fisik sesuai dengan komponen kebugaran jasmani dengan pendekatan atau cara yang sesuai dengan petunjuk pelaksanaannya (Santoso, 2016).

Kebugaran jasmani sangat dipengaruhi oleh faktor usia, jenis kelamin, faktor bawaan dari lahir (genetik), asupan makanan dan pembiasaan pola hidup sehat (Yusuf, 2018). Perlu diperhatikan juga dalam pelatihan kebugaran jasmani sangat dipengaruhi oleh kebutuhan oksigen dalam tubuh agar mampu menyelesaikan program latihan dengan baik, kebutuhan akan oksigen $\left(\mathrm{VO}_{2}\right)$ bagi mahluk hidup sangat diperlukan agar dapat bernafas, semua jenis makanan yang masuk kedalam tubuh manusia bereaksi membentuk energi, uap air $\left(\mathrm{H}_{2} \mathrm{O}\right)$ dan karbondioksida $\left(\mathrm{CO}_{2}\right)$ (Pamungkas \& Nidomuddin, 2019). Program pelatihan kebugaran jasmani dapat mengidentifikasi juga kondisi kesehatan seseorang (Joensuu et al., 2018). 
Program pelatihan kebugaran jasmani lebih menekankan pada program keterampilan kondisi jasmani diantaranya lari 1200 meter, lari 60 meter, pull-up selama 1 menit, push-up selama 1 menit, sit-up selama 1 menit, vertical jump, program pelatihan yang dibuat harus merujuk pada komponen tes kebugaran jasmani agar tercapai hasil yang maksimal. Penelitian ini juga terdukung oleh beberapa data hasil penelitian yang diteliti oleh (Rusdi, Arifin Zainal, 2016) dengan judul penelitiannya "Survei Kebugaran Jasmani Atlet Renang Usia 10-12 Tahun dengan hasil penelitiannya mengukur tingkatan kondisi kebugaran atlet renang usia 10-12 tahun, perbedaann penelitian pada peneliti lakukan pada usia atlet, peneliti melakukan penelitian pada atlet renang usia 16-19 tahun, selain itu juga terdukung oleh hasil penelitian (Sookermany \& Sand, 2019) dengan judul penelitiannya "The physical fitness test discourse model" dengan hasil penelitiannya bahwa tes kebugaran jasmani memberikan peningkatan fisik pada kinerja prajurit di militer, perbedaan penelitiannya pada item tes yang digunakan yaitu menggunakan item tes pengukuran indeks massa tubuh (BMI), tes daya tahan otot, kekuatan otot dan fleksibilitas, dan populasinya pada anggota militer sedangkan peneliti menggunakan tes yang mengacu pada pedoman tes kebugaran jasmani indonesia (TKJI) usia 16-19 tahun. Penelitian juga terdukung oleh penelitian yang dilakukan oleh (Akbar, Haris Mohammad, Wisnu, 2015) dari penelitiannya terkait "Survei Tingkat Kebugaran Jasmani Siswa Kelas X, XI dan XII SMAN 3 Nganjuk" perbedaan penelitiannya pada populasi dan sampel yang dipilih peneliti melakukan penelitian pada tingkatan mahasiswa. Dengan adanya penelitian yang mendukung dengan peneliti ini akan lebih menguatkan bahwa faktor kebugaran jasmani itu merupakan faktor penting dalam menunjang tercapainya prestasi seseorang lebih optimum, dan setiap program pelatihan yang dibuat akan tercapai tujuan pelatihannya karena atlet memiliki tingkat kondisi bugar yang tinggi.

\section{SIMPULAN}

Didasarkan pada hasil penelitian dan analisis data yang disajikan terkait tingkat kebugaran jasmani atlet renang UNSIKA, maka kesimpulannya adalah bahwa tingkat kebugaran jasmani atlet renang UNSIKA berada pada kategori 
sedang, atau sekitar 35\%, ini berarti kualitas kebugaran jasmani atlet renang UNSIKA harus terus ditingkatkan. Dari hasil penelitian ini bahwa pentingnya tes kebugaran jasmani bagi atlet khususnya atlet renang yang terbiasa melakukan tes kebugaran jasmani di kolam renang. Dengan dilakukannya tes kebugaran jasmani secara periodik akan dipastikan tingkat kebugaran jasmani atlet semakin meningkat. Untuk para pelatih dan atlet renang harus selalu melakukan tes kebugaran jasmani baik di darat maupun di kolam renang secara periodik agar mendapatkan kondisi kebugaran jasmani yang optimal sehingga akan berkontribusi dalam pencapaian hasil perlombaan yang ditargetkan.

\section{DAFTAR RUJUKAN}

Akbar, Haris Mohammad, Wisnu, H. (2015). Survei Tingkat Kebugaran Jasmani Siswa Kelas X, XI dan XII SMAN 3 NGANJUK. Jurnal Pendidikan Olahraga Dan Kesehatan, 03(3), 702-708. Retrieved from http://ejournal.unesa.ac.id/index.php/jurnal-pendidikan-jasmani/issue/archive

Catikkas, F. (2016). Sexual dimorphism in physical fitness parameters of competitive adolescent taekwondo athletes. Anthropologist, 25(1-2), 70-75. https://doi.org/10.1080/09720073.2016.11892090

Dartini, Sucita Dwi Putu Ni, Suwiwa, Gede I, S. P. L. (2017). Tingkat Kebugaran Jasmani Siswa Kelas V Sekolah Dasar Gugus VI Kecamatan Sukasada. Jurnal Penjakora, 4(1), 27-37. https://doi.org/http://dx.doi.org/10.23887/penjakora.v4i1.11751

Fenanlampir, A., Faruq, M. M.. (2015). Tes dan pengukuran dalam olahraga. Yogyakarta .CV. Andi Offset.

Hanief, Y. N., \& Himawanto, W. (2017). Statistik Pendidikan. Yogyakarta. Deepublish.

Iskandar. (2014). Survey Tingkat Kebugaran Jasmani Mahasiswa Baru Penjaskes Stkip-Pgri Pontianak Tahun 2013. Jurnal Pendidikan Olahraga, 3(1), 15-26. https://doi.org/http://dx.doi.org/10.31571/jpo.v3i1.134

Joensuu, L., Syväoja, H., Kallio, J., Kulmala, J., Kujala, U. M., \& Tammelin, T. H. (2018). Objectively measured physical activity, body composition and physical fitness: Cross-sectional associations in 9- to 15-year-old children. European Journal of Sport Science, 18(6), 882-892. https://doi.org/10.1080/17461391.2018.1457081

Kusuma Wijaya, I. D. M. A. (2019). Perbedaan tingkat vo2max awal memiliki dampak yang berbeda terhadap hasil latihan Tabata. Jurnal SPORTIF: Jurnal Penelitian Pembelajaran, 5(2), 327-341. 
https://doi.org/https://doi.org/10.29407/js_unpgri.v5i2.13490

Lazar, J. M., Khanna, N., Chesler, R., \& Salciccioli, L. (2013). Swimming and the heart. International Journal of Cardiology, 168(1), 19-26. https://doi.org/10.1016/j.ijcard.2013.03.063

Mubarok, M. Z. (2019). Pengaruh Latihan Small Sided Games Mengunakan Metode Interval Terhadap Peningkatan Dribbling Pemain Sepakbola. Biormatika: Jurnal Ilmiah Fakultas Keguruan Dan Ilmu Pendidikan, 5(02), 144-149. https://doi.org/10.35569/biormatika.v5i02.513

Nanda Yudianti, M. (2016). Profil Tingkat Kebugaran Jasmani (Vo2max) Atlet Hockey (Field) Putri SMAN 1 Kedungwaru Tulungagung. Jurnal Kesehatan Olahraga, 4(2), 120-126.

Nugraheningsih, G., \& Saputro, Y. A. (2019). Peningkatan Kesegaran Jasmani Melalui Matakuliah Pencaksilat Mahasiswa Ilmu Keolahragaan. Jp.Jok(Jurnal Pendidikan. Jasmani , Olahraga Dan Kesehatan), 3(1), 13-26. Retrieved from http://ejurnal.budiutomomalang.ac.id/index.php/jpjok Jp.jok

Nugroho, D. P. (2017). Status Kebugaran Jasmani Atlet Anggar Kulon Progo Usia 13- 19 Tahun Dalam Persiapan Porda 2017 Di Bantul. Pendidikan Jasmani Kesehatan Dan Rekreasi, 7(12), 3-9. Retrieved from http://journal.student.uny.ac.id/ojs/index.php/pjkr/article/view/10333/9894

Pamungkas, H., \& Nidomuddin, M. (2019). Korelasi Oksigen Dalam Darah Dengan Vo 2 Max. Jp.Jok (Jurnal Pendidikan. Jasmani, Olahraga Dan Kesehatan), 3(1), 82-89. Retrieved from http://ejurnal.budiutomomalang.ac.id/index.php/jpjok Jp.jok

Prasetyo, Y. (2013). Kesadaran Masyarakat Berolahraga untuk Peningkatan Kesehatan dan Pembangunan Nasional. Medikora, 11(2), 219-228. Retrieved from https://journal.uny.ac.id/index.php/medikora/article/download/2819/2344

Pratiwi, F. Z., Setijono, H., \& Fuad, Y. (2018). Effect of Plyometric Front Cone Hops Training and Counter Movement Jump Training to Power and Strenght of Leg Muscles. Jurnal SPORTIF: Jurnal Penelitian Pembelajaran, 4(1), $105-119$.

Prayuda, A. Y., \& Firmansyah, G. (2017). Pengaruh Latihan Lari 12 Menit Dan Lari Bolak Balik Terhadap Peningkatan Daya Tahan VO2 max. JP.JOK (Jurnal Pendidikan Jasmani, Olahraga Dan Kesehatan), 1(1), 13-22. https://doi.org/10.33503/jpjok.v1i1.247

Pujianto, A. (2015). Profil Kondisi Fisik Dan Keterampilan Teknik Dasar Atlet Tenis Meja Usia Dini Di Kota Semarang. Journal of Physical Education, Health and Sport, 2(1), 38-43.

Pyne, D. B., \& Sharp, R. L. (2014). Physical and energy requirements of competitive swimming events. International Journal of Sport Nutrition and 
Exercise Metabolism, 24(4), 351-359. https://doi.org/10.1123/ijsnem.20140047

Rusdi, Arifin Zainal, A. (2016). Survei Kebugaran Jasmani Atlet Renang Usia 1012 Tahun. Jurnal Pendidikan Olahraga, 5(1), 38-45. https://doi.org/http://dx.doi.org/10.31571/jpo.v5i1.312

Santoso, D. A. (2016). Analisis Tingkat Kebugaran Jasmani Atlet Bolavoli Putri Universitas PGRI Banyuwangi. Jurnal Kejaora, 1(April), 37-46.

Saputro, Y. D. (2018). Survei Tingkat Kebugaran Jasmani Pada Siswa Putri Kelas VIII MTS Surya Buana Malang Tahun Pelajaran 2017/2018. Jp. Jok (Jurnal Pendidikan Jasmani, Olahraga Dan Kesehatan), 1(2), 92-101.

Satrio, B., \& Winarno, E. (2019). Kualitas kebugaran jasmani peserta ekstrakurikuler olahraga. Jurnal SPORTIF : Jurnal Penelitian Pembelajaran, 5(2), 312-326. https://doi.org/https://doi.org/10.29407/js_unpgri.v5i2.13069

Sepriadi. (2017). Pengaruh Motivasi Berolahraga Dan Status Gizi Terhadap Tingkat Kebugaran Jasmani. Jurnal Penjakora, 4(1), 77-89. https://doi.org/http://dx.doi.org/10.23887/penjakora.v4i1.11755

Sookermany, A. M. D., \& Sand, T. S. (2019). The physical fitness test discourse model. Cogent Social Sciences, 5(1). https://doi.org/10.1080/23311886.2019.1615241

Supriyoko, A., \& Mahardika, W. (2018). Kondisi Fisik Atlet Anggar Kota Surakarta. Jurnal SPORTIF: Jurnal Penelitian Pembelajaran, 4(2), 280. https://doi.org/10.29407/js_unpgri.v4i2.12540

Tarsito, S. (2014). Metode Penelitian Kuantitatif, Kualitatif dan R\&D. Alfabeta. Bandung.

Wahyudi, Andra, Rahayu Kaswarganti, S. (2015). Kondisi Kesegaran Jasmani Atlet Perkumpulan Renang Tirta Wahana Usia 10 - 12 Tahun. Journal of Sport Sciences, 4(1), 12-16. Retrieved from https://journal.unnes.ac.id/sju/index.php/ujss/article/view/8633

Wirnantika, I., Pratama, B. A., \& Hanief, Y. N. (2017). Survey Tingkat Kebugaran Jasmani Siswa Kelas IV SDN Puhrubuh I dan MI Mambaul Hikam di Kabupaten Kediri Tahun Ajaran 2016/2017. Sportif, 3(2), 240250. https://doi.org/10.29407/js_unpgri.v3i2.11898

Yusuf, H. (2018). Evaluasi Kebugaran Jasmani Melalui Harvard Step Test pada Mahasiswa pjkr Tahun2016/2017 IKIP Budi Utomo. Jp. Jok (Jurnal Pendidikan Jasmani, Olahraga Dan Kesehatan), 1(2), 1-13. 